\title{
Effects of Interventricular Shunt on Indices of Left Ventricular Function
}

\author{
SUGURU MATSUOKA, HIROFUMI TOMIMATSU, YOSHIO MIYAUCHI, TADANORI NAKATSU, \\ YASUHITO YUASA, AND MASUHIDE MIYAO \\ Department of Pediatrics, School of Medicine, Tokushima University, Kuramoto-cho, Tokushima, Japan
}

\begin{abstract}
The accuracies of indices of left ventricle function were examined in an open-chest model in dogs with and without a ventricular septal defect, in which the ventricular shunt was opened and reclosed by a specially designed flowmeter probe with a cap. The systolic time interval, the maximal rate of pressure development in the left ventricle $(+L V \mathrm{dP} / \mathrm{dt}),+L V \mathrm{dP} / \mathrm{dt}$ corrected for the isometric pressure $(+\mathrm{LV} \mathrm{dP/dt} / \mathrm{Pd})$, and the time to $+\mathrm{LV}$ $\mathrm{dP} / \mathrm{dt}(\mathrm{t}-\mathrm{dP} / \mathrm{dt})$ were determined by recording the aortic flow, ventricular shunt flow, aortic pressure, pulmonary arterial pressure, and left ventricular pressure. The isometric contraction time, the preejectional period, and the ejection time shortened with decrease of the mean aortic pressure and aortic flow, and the mean pulmonary arterial pressure increased after opening the ventricular shunt. When the pulse was varied by atrial pacing, the systolic time interval was affected in dogs both with and without a ventricular septal defect, but "isometric contraction time" was not affected in animals with a ventricular septal defect. Dopamine and methoxamine were used to evaluate the effects of the inotropic state and afterload on these indices. The extents of the changes in the systolic time interval and $+\mathrm{LV} \mathrm{dP} / \mathrm{dt}$ were different in animals with and without a ventricular septal defect, but the changes in preejectional period/ejection time, $+\mathrm{LV} \mathrm{dP/dt/Pd}$ and $\mathrm{t}-\mathrm{dP} / \mathrm{dt}$ were similar in the two conditions. These results suggest that the systolic time interval and the indices of left ventricular pressure are useful in assessment of cardiac function only in certain conditions. (Pediatr Res 20: 433-437, 1986)
\end{abstract}

\section{Abbreviations}

VSD, ventricular septal defect

ICT, isometric contraction time in the VSD animals.

$+\mathrm{LV} \mathrm{dP/dt,} \mathrm{maximal} \mathrm{rate} \mathrm{of} \mathrm{pressure} \mathrm{development} \mathrm{in} \mathrm{the}$ left ventricle

$+\mathrm{LV} \mathrm{dP/dt/Pd,}+\mathrm{LV} \mathrm{dP/dt}$ corrected for the isometric pressure

$t-d P / d t$, time to $+\mathrm{LV} \mathrm{dP/dt}$ (from the $\mathrm{R}$ wave of the ECG

to $+L V d P / d t)$

ET, ejection time

PEP, preejectional period

Many indices of left ventricular function are available, such as the ejection fraction, the systolic time interval, the first derivative of the left ventricular pressure, and indices from the pressurevolume curve. However, it is uncertain whether these indices are

Received September 9, 1985; accepted January 6, 1986.

Address for correspondence and reprints Dr. Suguru Matsuoka, Department of Pediatrics, School of Medicine, Tokushima University, Kuramoto-cho, Tokushima, 770 , Japan. useful for evaluating cardiac function in patients with a VSD as well as in those without a VSD, since in patients with a VSD, the ICT is shortened or absent $(1,2)$, and the cardiac geometry and structure are changed by increase of the left ventricular enddiastolic volume and pressure $(2,3)$, and these changes may affect the indices of cardiac function. An ideal index of cardiac contractility should not be affected by preload and afterload, but no ideal index for patients with a VSD is available.

Cardiac function is difficult to assess clinically, because patients all have different locations and sizes of defects, grades of pulmonary vascular resistance, extents of outflow obstruction of the right ventricle, and thicknesses and stiffnesses of cardiac muscle (4). We examined the effects of interventricular shunt on the systolic time interval and the indices from the left ventricle pressure curve in different contractile states induced by drugs in the same cardiac muscle using an experimental model of VSD.

\section{MATERIALS AND METHODS}

Twenty-one adult mongrel dogs weighing 10 to $13 \mathrm{~kg}$ were used. They were anesthetized by intravenous injection of $30 \mathrm{mg} /$ $\mathrm{kg}$ of sodium thiopental, and after insertion of an endotracheal tube, they were ventilated with a tidal volume of $300 \mathrm{ml}$ from a positive pressure respirator (Igarashi Respirator Model B2). The heart and great vessels were exposed by a midline sternotomy. A cylindrical cutter was introduced through a right ventricular purse-string suture and forced through the ventricular septum to create a perimembranous defect. A 6-mm core of septal tissue was excised from the interventricular septum with the cylindrical cutter and then a specially designed flow-meter probe $(6 \mathrm{~mm}$ inner lumen diameter, $8 \mathrm{~mm}$ outer diameter, $10 \mathrm{~mm}$ length, Nihon Koden Kogyo Co.) was promptly placed in the VSD. With this probe the VSD could be opened and reclosed by a cap that was attached to threads running through the apex of the left ventricle and the free wall of the right ventricle, respectively.

The position of the cutter in the interventricular septum was critical because it was essential not to damage the aortic valve or the chordae tendineae of the tricuspid valve. A suitable sized flowmeter probe (lumen diameter 10 or $12 \mathrm{~mm}$, Nihon Koden Kogyo Co.) was cannulated in the ascending aorta for continuous monitoring of the systemic blood flow. The intracorporeal and aortic probes were connected to a square-wave electromagnetic flowmeter of constant diameter (model MF-27, Nihon Koden Kogyo Co.), which simplified measurement of the minute volume. The flowmeter probe gave an accurate response when calibrated in vitro with flows of 0 to 2 liter/min. The diastolic level of the aortic pulsatile flow was used as zero reference in measurement of systemic blood flow in vivo. The zero value of shunt flow was easily obtained by closing the intracorporeal probe with the cap. Pressures were measured with Millar Instrument $4 \mathrm{~F}-6 \mathrm{~F}$ catheter-tip micromanometers, which were placed in the ascending aorta, main pulmonary artery, and left ventricle. The details of this system have been described previously (5). 
After production of a VSD, a period of 20-30 min was allowed for hemodynamic stabilization. When all the hemodynamic parameters had become stable, the shunt was opened and the effects of acute left to right shunting were observed.

The ECG, pulmonary arterial pressure, aortic pressure, left ventricular pressure, the first derivative of the left ventricular pressure, $(\mathrm{LV} \mathrm{dP} / \mathrm{dt})$, the aortic flow, and the velocity curve of shunt flow were recorded on a Mingograph (model 800).

As parameters of left ventricular function, the following indices were calculated (Fig. 1): 1) the ET of the left ventricle, from the aorta upstroke to the dicrotic notch in the aortic pressure curve; 2) the PEP of the left ventricle, from the onset of the QRS wave of the ECG to the upstroke point in the aortic pressure curve; 3 ) the isometric contraction time of the left ventricle (ICT), from the upstroke point in the left ventricular pressure curve to the upstroke point in the aortic pressure curve; 4) the maximal rate of left ventricular pressure development (+ LV dP/dt), the maximum value of the first derivative of left ventricular pressure; 5) the ratio of the maximal rate of left ventricular pressure development to the simultaneously occurring isometric pressure $(+$ $\mathrm{LV} \mathrm{dP} / \mathrm{dt}$ )/Pd, $+\mathrm{LV} \mathrm{dP} / \mathrm{dt}$ divided by the instantaneous left ventricular pressure minus the left ventricular end-diastolic pressure, and 6) the time to the maximal rate of left ventricular pressure development $(\mathrm{t}-\mathrm{dP} / \mathrm{dt})$, from the $\mathrm{R}$ wave of the ECG to the maximal rate of left ventricular pressure development.

Twenty-one dogs were divided into four groups. The five animals in group I served as controls for the time course and were monitored without pharmacologic intervention for $180 \mathrm{~min}$ after opening the interventricular shunt.

Hemodynamic parameters were allowed to stabilize for at least 20 min after creation of the defect, and then right atrial pacing was started in group II and drugs were infused in groups III and IV.

In group II of five dogs, the heart rate was changed by right atrial pacing in the range of 120 and 210 beats/min to study the effects of the heart rate on the indices of left ventricular function. Atrial pacing was performed for $20 \mathrm{~min}$ with and without a shunt at each pacing rate. Within a few minutes after the ventricular shunt was reclosed, all hemodynamic values returned to those obtained before opening the shunt.
The seven dogs in group III were given dopamine at doses of 5,10 , and $20 \mu \mathrm{g} / \mathrm{kg} / \mathrm{min}$ for $20 \mathrm{~min}$. The five dogs in group IV were given methoxamine at a dose of $0.01 \mathrm{mg} / \mathrm{kg} / \mathrm{min}$ for 20 min. The effects of the drugs were evaluated as percentage changes from the control values. The control value of each index was that before injection of dopamine or methoxamine with or without a shunt. Hemodynamic changes were examined several times by closing and reopening the shunt (Fig. 1).

Statistical evaluation of the significance of hemodynamic changes and the indices of left ventricular function were examined by the paired $t$ test, taking a $p$ value of less than 0.05 as significant.

\section{RESULTS}

Significant hemodynamic effects occurred immediately after opening or reclosing the shunt and became stable within a few minutes. Analysis of variance showed no significant variation in the hemodynamic changes and the indices of left ventricular function for $180 \mathrm{~min}$ after opening or reclosing the shunt. All measurements in the test animals were completed within 180 min after creation of the septal defect.

1) Effects of the acute presence of a shunt on hemodynamic changes and indices of left ventricular function.

After opening the shunt, the mean aortic pressure and aortic flow decreased with increase in the mean pulmonary arterial pressure as shown in Table 1 . These results in dogs with a VSD showed that the VSD was moderate (pulmonary to systemic flow ratio $=2.42 \pm 0.38$ ) and that the pulmonary vascular bed was normal. Although the mean aortic pressure, mean pulmonary arterial pressure, and pulmonary to systemic flow ratio changed remarkably, PEP/ET, + LV dP/dt, $(+\mathrm{LV} \mathrm{dP} / \mathrm{dt}) / \mathrm{Pd}$, and $\mathrm{t}-\mathrm{dP} /$ dt did not change significantly, and ICT, ET, and PEP decreased significantly.

2) Effects of atrial pacing on hemodynamic changes and indices of left ventricular function in dogs with and without a VSD.

Figures 2 and 3 show that the mean aortic pressure, aortic flow, shunt flow, PEP, and ICT decreased in atrial tachycardia. The PEP was correlated with the atrial pacing rate with and

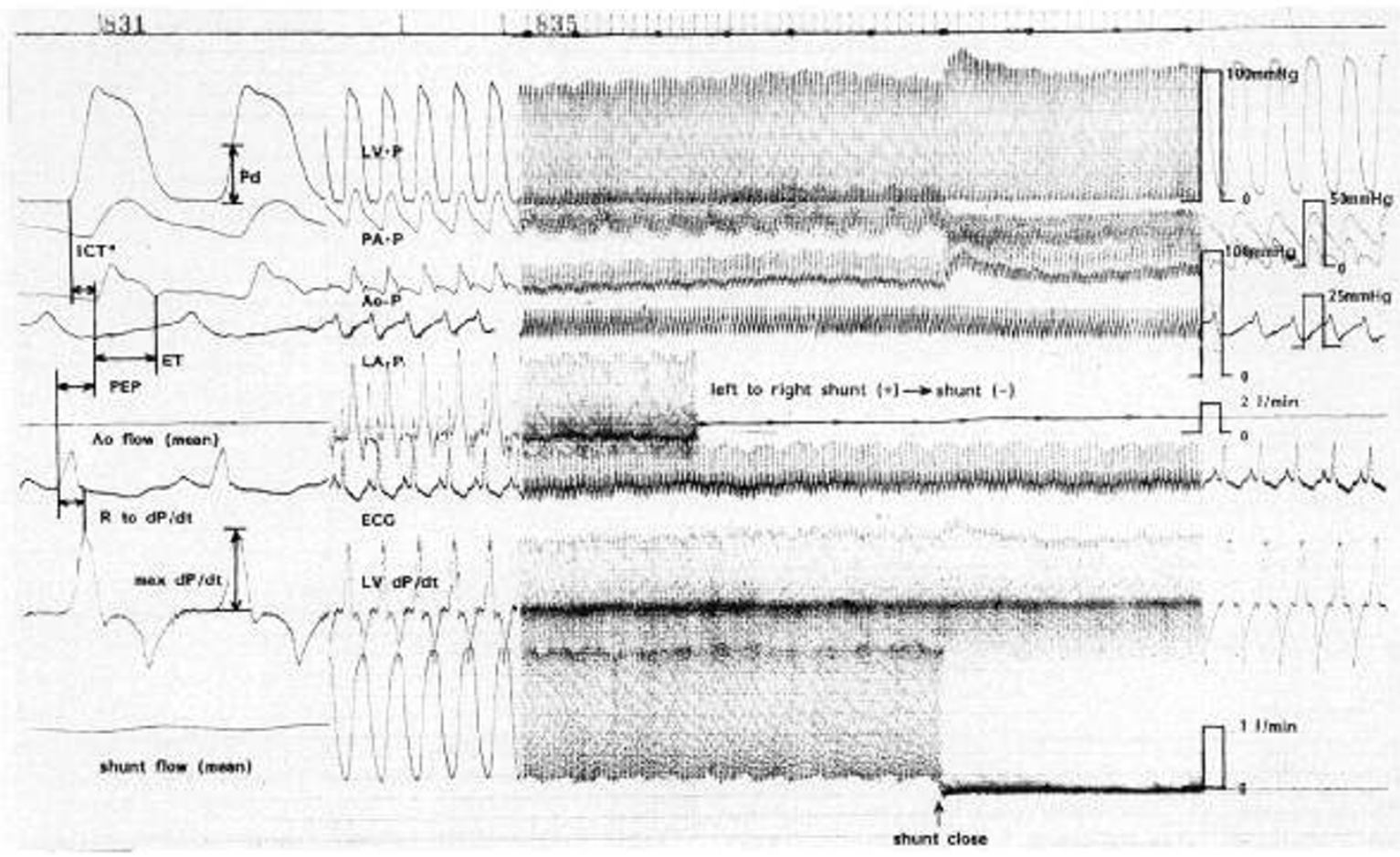

Fig. 1. Effects of closing the ventricular shunt on hemodynamics. $L V d P / d t$, first derivative of left ventricular pressure; $A o F$, aortic flow. 
without a shunt. The data were analyzed by the linear regression equation $\mathrm{PEP}=-0.27 \times$ pacing rate $+117(r=-0.84, p<$ $0.001)$ with a shunt, and PEP $=-0.13 \times$ pacing rate $+86(r=$ $-0.53, p<0.001)$ without a shunt. The ICT was correlated with the atrial pacing rate without a shunt, ICT $=-0.14 \times$ pacing rate $+66(r=-0.41, p<0.01)$, but showed no correlation with the heart rate in dogs with a shunt. In contrast, the mean pulmonary arterial pressure, $+\mathrm{LV} \mathrm{dP/dt}, \mathrm{PEP} / \mathrm{ET},(+\mathrm{LV} \mathrm{dP} /$ $\mathrm{dt}) / \mathrm{Pd}$, and $\mathrm{t}-\mathrm{dP} / \mathrm{dt}$ did not change significantly at pacing rates of 120 to $210 / \mathrm{min}$ either with or without a shunt.

Table 1. Basic hemodynamic data before and after opening a ventricular shunt*

\begin{tabular}{lcccc}
\hline & Close & Open & \% Change & $p$ value \\
\hline Heart rate (/min) & $125 \pm 15$ & $131 \pm 21$ & $+3 \pm 6$ & NS \\
Mean Ao pressure & $84 \pm 18$ & $66 \pm 12$ & $-19 \pm 4$ & $<0.01$ \\
$\quad$ (mm Hg) & & & & \\
Mean PA pressure & $18 \pm 5$ & $28 \pm 7$ & $+53 \pm 21$ & $<0.01$ \\
$\quad$ (mm Hg) & & & & \\
Aortic flow (liter/ & $1.12 \pm 0.25$ & $0.88 \pm 0.24$ & $-18 \pm 7$ & $<0.01$ \\
$\quad$ min) & & $1.25 \pm 0.28$ & & \\
Shunt flow (liter/ & & & & \\
$\quad$ min) & & & & \\
Qp/Qs ratio & 1.0 & $2.42 \pm 0.38$ & $142 \pm 38$ & $<0.01$ \\
ICT (ms) & $43 \pm 15$ & $33 \pm 9$ & $-18 \pm 13$ & $<0.01$ \\
PEP (ms) & $80 \pm 15$ & $62 \pm 10$ & $-20 \pm 6$ & $<0.01$ \\
PEP/ET (ms) & $0.44 \pm 0.07$ & $0.42 \pm 0.05$ & $-3 \pm 7$ & NS \\
+ LV dP/dt (mm & $3300 \pm 620$ & $3100 \pm 650$ & $-2 \pm 2$ & NS \\
$\quad$ Hg/s) & & & & \\
$(+\mathrm{LV} \mathrm{dP/dt)/Pd}(/$ & $40 \pm 8$ & $45 \pm 8$ & $+5 \pm 9$ & $\mathrm{NS}$ \\
$\quad$ s) & & & & \\
$\mathrm{t}-\mathrm{dP} / \mathrm{dt}(\mathrm{ms})$ & $71 \pm 10$ & $70 \pm 12$ & $-2 \pm 3$ & $\mathrm{NS}$ \\
\hline
\end{tabular}

* All values are means $\pm \mathrm{SD}, n=21$. Abbreviations: Ao $=$ aorta, $\mathrm{PA}$ $=$ pulmonary artery, $\mathrm{Qp} / \mathrm{Qs}=$ pulmonary to systemic flow ratio, $\mathrm{LV}=$ left ventricle.
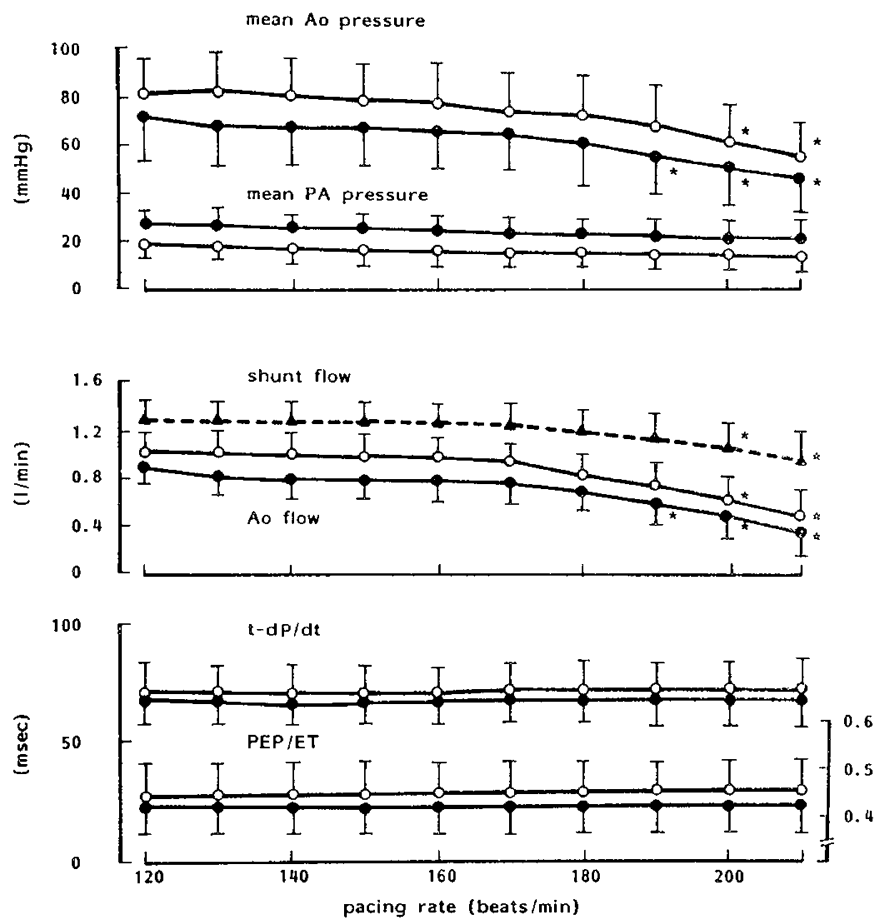

Fig. 2. Effects of atrial pacing on left-to-right shunt flow, aortic flow and the $\mathrm{Qp} / \mathrm{Qs}$ ratio. * significantly different $(p<0.05)$ from the value at 120 beats $/ \mathrm{min}$. Points and bars are means \pm S.D. Close circles and open circles show values with and without a VSD, respectively.

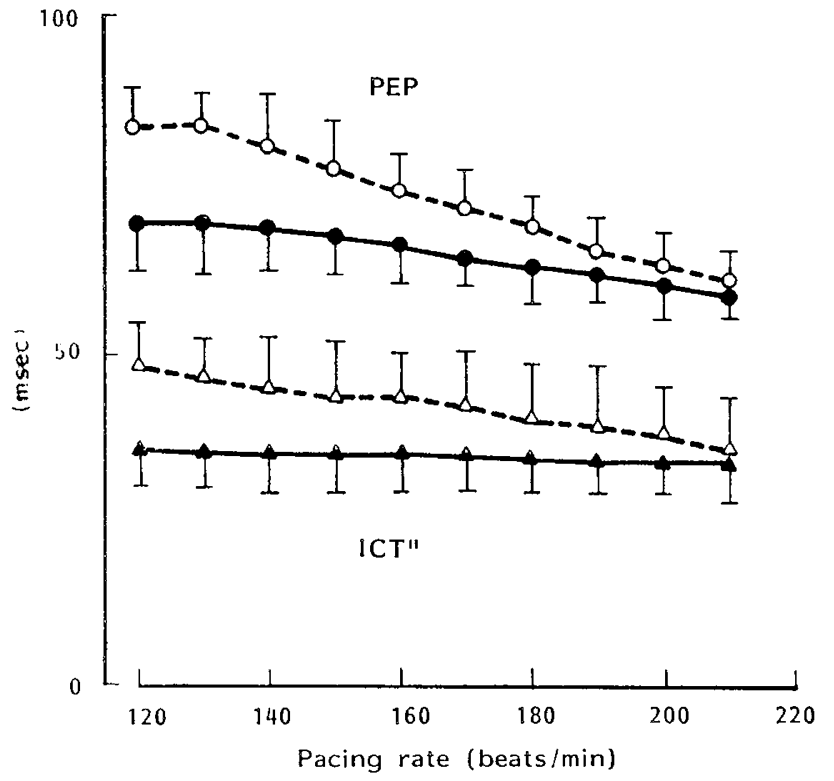

Fig. 3. Effects of atrial pacing on PEP and ICT. The solid line and dashed line show results with and without a shunt, respectively.

Table 2. Effects of dopamine on hemodynamic changes*

\begin{tabular}{lcccc}
\hline & Zero & \multicolumn{3}{c}{ \% Change of each parameter } \\
\cline { 3 - 5 } & & 5 & 10 & 20 \\
\hline Heart rate $(/ \mathrm{min})$ & & & & \\
Shunt $(-)$ & $131 \pm 21$ & $-2 \pm 4$ & $+2 \pm 5$ & $+2 \pm 8$ \\
Shunt $(+)$ & $139 \pm 27$ & $+1 \pm 4$ & $+2 \pm 5$ & $+3 \pm 11$ \\
$p$ valuet & NS & NS & NS & NS
\end{tabular}

Mean Ao P (mm

$\mathrm{Hg})$

Shunt (-) $\quad 76 \pm 12 \quad+13 \pm 6 \ddagger \quad+36 \pm 16 \ddagger+55 \pm 20 \ddagger$

Shunt $(+) \quad 65 \pm 10 \quad+9 \pm 5 \ddagger \quad+21 \pm 8 \ddagger \quad+37 \pm 18 \ddagger$

$p$ value $\quad$ NS $\quad$ NS NS NS

Mean PA P (mm

$\mathrm{Hg}$ )

$\begin{array}{lcccc}\text { Shunt }(-) & 15 \pm 4 & +26 \pm 10 \ddagger & +59 \pm 19 \ddagger & +87 \pm 27 \ddagger \\ \text { Shunt }(+) & 22 \pm 4 & +12 \pm 8 \ddagger & +36 \pm 14 \ddagger & +46 \pm 21 \ddagger \\ p \text { value } & <0.01 & <0.01 & <0.01 & <0.01\end{array}$

Ao flow (liter/ $\min$ )

Shunt $(-) \quad 1.22 \pm 0.17+17 \pm 10 \ddagger+33 \pm 18 \ddagger+56 \pm 25 \ddagger$

Shunt $(+) \quad 0.90 \pm 0.20+8 \pm 6 \ddagger \quad+20 \pm 14 \ddagger+28 \pm 18 \ddagger$

$p$ value $\quad<0.01 \quad$ NS $\quad$ NS $<0.05$

Shunt flow (liter/ $\min )$

Shunt (-)

Shunt $(+)$

$p$ value

$\begin{array}{cccc}0 & 0 & 0 & 0 \\ 0.92 \pm 0.22 & -28 \pm 17 \ddagger & -51 \pm 20 \ddagger & -63 \pm 18 \ddagger \\ <0.01 & <0.01 & <0.01 & <0.01\end{array}$

* All values are means $\pm \mathrm{SD}, n=6$.

$\uparrow$ Significance of difference in values with and without a shunt.

$\ddagger \S$ Significant difference between values before and after dopamine infusion $(\ddagger 0.01<p<0.05, \S p<0.01)$.

3) Effects of dopamine on hemodynamic changes and the indices of left ventricular function in dogs with and without a VSD.

Table 2 shows that dopamine increased the mean aortic pressure, mean pulmonary arterial pressure, and aortic flow with 
decrease of left-to-right shunt flow. The percentage changes of mean aortic pressure, mean pulmonary arterial pressure, and aortic flow were less with a shunt than without a shunt. Figure 4 shows the percentage changes of the indices during infusion of dopamine at doses of 5,10 , and $20 \mu \mathrm{g} / \mathrm{kg} / \mathrm{min}$. Change in $+\mathrm{LV}$ $\mathrm{dP} / \mathrm{dt}$ was the greatest, and that in PEP/ET was the smallest.

The results indicate that the effects of dopamine at $20 \mu \mathrm{g} / \mathrm{kg} /$ min on PEP/ET, $(+\mathrm{LVdP} / \mathrm{dt}) / \mathrm{Pd}$, and $\mathrm{t}-\mathrm{dP} / \mathrm{dt}$ were similar with and without a shunt, whereas the effects on ICT, PEP, and $+\mathrm{LV} \mathrm{dP} / \mathrm{dt}$ were less with a shunt than without a shunt.

4) Effects of methoxamine on the hemodynamic changes and indices of left ventricular function.

Methoxamine decreased the values of ICT, PEP, PEP/ET, and $\mathrm{t}-\mathrm{dP} / \mathrm{dt}$ and increased that of $+\mathrm{LV} \mathrm{dP} / \mathrm{dt}$ with a significant increase of the mean aortic pressure and shunt flow (Fig. 5). The effects of methoxamine on ICT, PEP, and $+\mathrm{LV} \mathrm{dP/dt}$ were less
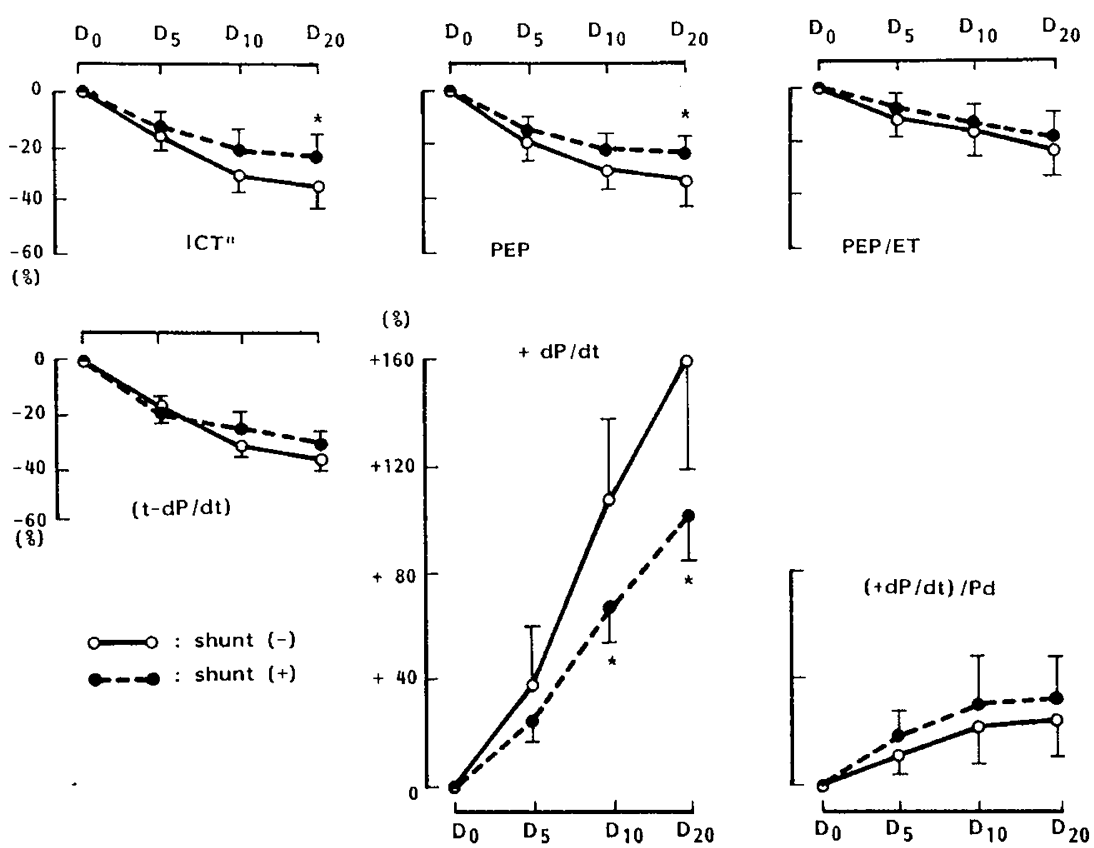

Fig. 4. Effects of dopamine infusion on indices of left ventricular function. Horizontal axes show the dose of dopamine $(0,5,10,20 \mu \mathrm{g} / \mathrm{kg} / \mathrm{min})$. Vertical axes show percent changes of the indices from the value before dopamine injection. ${ }^{*}$ significant difference $(p<0.01)$ between values with and without a shunt. Points and bars are means \pm S.D. Bars indicate values with a shunt $(n=7)$.
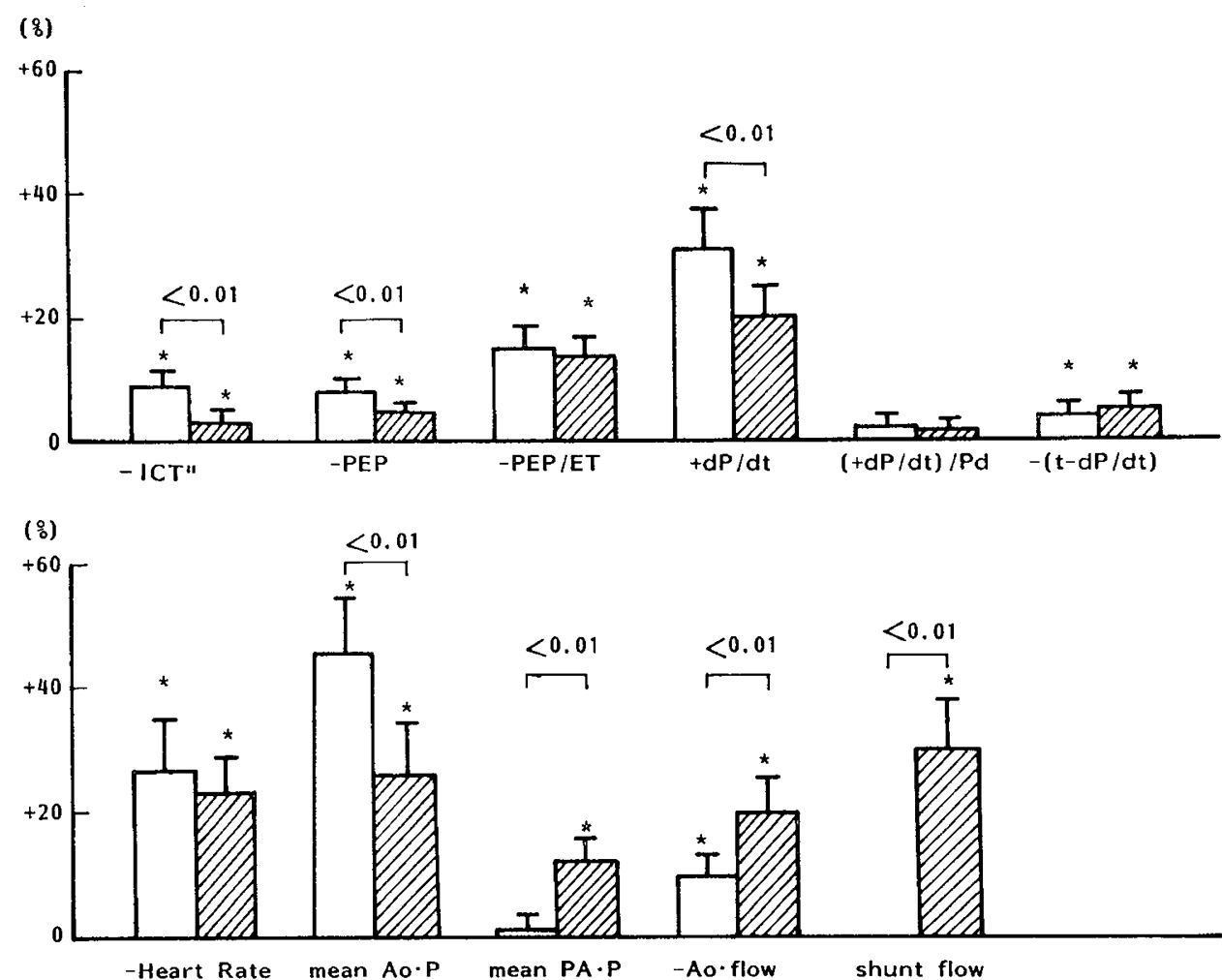

Fig. 5. Effects of methoxamine infusion on the indices of left ventricular function and hemodynamic changes. Vertical axes show percent changes from the value before methoxamine infusion. ${ }^{*}$ significantly different $(p<0.05)$ from the value before methoxamine infusion. $p$ values for differences with and without a VSD are shown $(n=5)$. 
with a shunt than without a shunt. These results indicate that change in the afterload affects indices of cardiac function such as ICT, PEP, PEP/ET, +LV dP/dt, and $\mathrm{t}-\mathrm{dP} / \mathrm{dt}$.

\section{DISCUSSION}

The ICT has been measured in patients with a VSD $(6,7)$. However, left-to-right ventricular shunt begins before opening of the aortic valve $(1,2)$. This indicates that ICT is not a real isometric measure in patients with a VSD.

In this study ICT, PEP, and ET were shortened by opening a shunt, and affected by atrial pacing and the mean aortic pressure. Thus these indices were affected by not only the contractility, but also the preload, afterload, and heart rate. These results are consistent with previous findings (8).

The new findings in the present investigation were that the extents of the responses of the systolic time interval to atrial pacing, dopamine, and methoxamine were different with and without a VSD. The different responses of the systemic time interval to dopamine and methoxamine infusions with and without a shunt might account for the difference in hemodynamic changes shown in Table 2 and Figure 5 , because the direct pharmacologic effects of these drugs on the peripheral vasculature and cardiac muscle were the same with and without a VSD. Dopamine acts on $\alpha$ - and $\beta$-adrenergic receptors and has a direct positive inotropic action $(9,10)$, whereas methoxamine, an $\alpha$ adrenergic stimulant, has no direct effect on cardiac contractility (11).

These results suggest that ICT, PEP, and ET are not valid indices for evaluation of cardiac function in patients with a VSD as well as without a VSD. It seems that the shortened interval of ICT with a VSD was too short to be shortened further.

On the other hand, PEP/ET was not changed significantly by opening the interventricular shunt in this study. Similar tendencies of changes in PEP and ET might lead to reduced effects of opening the shunt and atrial pacing. A good index for evaluation of cardiac contractility should indicate the chronotropic response, but $\mathrm{PEP} / \mathrm{ET}$ did not show the chronotropic response in this study. This might be due to decrease in the filling volume of the left ventricle. The hemodynamic changes during tachycardia indicate decrease in output from the left ventricle (aortic flow plus left-to-right shunt) (Fig. 2). Another possibility is that the sensitivity of PEP/ET as an index of inotropism, and the change in PEP/ET during dopamine infusion were lowest (Fig. 4). These findings indicate that PEP/ET is not useful as an index of left ventricular contractility with a shunt.

Many previous investigators (12-14) have observed a close correlation between $+\mathrm{LV} \mathrm{dP} / \mathrm{dt}$ and contractility. Of the indices examined, $+\mathrm{LV} \mathrm{dP} / \mathrm{dt}$ was the most sensitive during dopamine infusion and methoxamine administration. However, the response with a shunt was not the same as that without a shunt. This difference was probably due to the smaller change in mean aortic pressure with a shunt than that without a shunt. Abrahamsen et al. (15) found that methoxamine increases left-to-right ventricular shunt flow in patients with a VSD. This finding is consistent with our results (Fig. 5). The difference in left ventricular end-diastolic volume and mean aortic pressure might also have an effect on $+\mathrm{LV} \mathrm{dP} / \mathrm{dt}$, since this index was affected by the preload and afterload (12-14). In this study, +LV dP/dt was not changed significantly by opening a shunt. This might be due to counter-action of the effect of a decrease in aortic pressure by an increase in left ventricular volume (aortic flow plus left-to- right shunt flow) on opening a shunt (Table 1). Thus $+\mathrm{LV} d \mathrm{P} /$ $\mathrm{dt}$ is not a good index of the contractile state under conditions in which preload and diastolic pressure are changing.

Mason et al. (13) showed that $+\mathrm{LV} \mathrm{dP} / \mathrm{dt}$ increased with development of isometric pressure and decreased with decrease of aortic pressure. After opening a shunt, the changes mentioned above would occur simultaneously.

Previous investigators $(13,16,17)$ showed that $(+\mathrm{LV} \mathrm{dP} / \mathrm{dt}) /$ $\mathrm{Pd}$ and $\mathrm{t}-\mathrm{dP} / \mathrm{dt}$ are very sensitive to change in the inotropic state and are also influenced to some extent by large changes in preload. Our study showed that both these indices were affected by an inotropic agent and were not affected by opening a shunt or change in the heart rate. The effect of the heart rate might be due to a combination of the chronotropic response and the effects of hemodynamic changes as described above for PEP/ET. Although $\mathrm{t}-\mathrm{dP} / \mathrm{dt}$ was influenced slightly by a large change in afterload (Fig. 5), this effect was similar with and without a shunt. These results indicate that $(+\mathrm{LV} \mathrm{dP} / \mathrm{dt}) / \mathrm{Pd}$ and $\mathrm{t}-\mathrm{dP} / \mathrm{dt}$ are more useful index as indices of left ventricular function than of cardiac contractility with and without a shunt.

Our results also showed that drug infusions resulted in different hemodynamic changes in animals with and without a VSD.

Our model is of acute VSD. The applicability of results with this model to the pathophysiology of chronic VSD requires further study.

\section{REFERENCES}

1. Levin AR, Spach MS, Canent RV, Boineau JP, Capp MP, Jain V, Barr RC 1967 Intracardiac pressure-flow dynamics in isolated ventricular septal defects. Circulation 35:430-441

2. Graham TP, Atwood G, Bousec RJ, Cordell GD, Boerth RC 1976 Right ventricular volume in ventricular septal defect. Circulation 54:800-804

3. Jarmakani MM, Graham TP, Canet RV, Spach MS, Capp MP 1969 Effect of site of shunt on left heart volume characteristics in children with ventricular septal defect and patent ductus arteriosus. Circulation 40:411-418

4. Graham TP, Bender HW, Spach MS 1983 Ventricular septal defect. In: Adams FH, Emmanouilides GC (eds) Heart Disease in Infants, Children and Adolescents. Williams \& Wilkins, Baltimore, pp134-154

5. Matsuoka S, Nakatsu T, Yuasa Y, Ueda H, Miyao M. 1985 Effect of respiratory acidosis on ventricular shunt flow and hemodynamics in dogs with ventricular septal defect. Jpn Circ J 49:499-506

6. Nesji OA 1980 Systolic time intervals in isolated ventricular septal defect in the adult. Circulation 62:609-614

7. Puviani G, Casa LD, Venezia L 1984 Systolic time intervals in isolated septal defects before and after corrective surgery. Cardiology 71:177-183.

8. Wallace AG, Mitchell JH, Skinner NS, Sarnoff SJ 1963 Duration of the phases of left ventricular systole. Circ Res 12:611-619

9. Black Wl. Rolett HL, Hill C 1968 Cardiovascular adrenergic activity of dopamine in the dog. Heart J 75:233-239

10. Goldberg LI 1972 Cardiovascular and renal actions of dopamine: potential clinical applications. Pharmacol Rev 24:1-29

11. Brewster WR, Os Good PE, Isaacs JP, Goldberg LI 1960 Hemodynamic effects of a pressor amine (methoxamine) with predominant vasoconstrictor activity. Circ Res 8:980-986

12. Mason DT 1969 Usefulness and limitation of the rate of rise of intraventricular pressure $(\mathrm{dP} / \mathrm{dt})$ in the evaluation of myocardial contractility in cardiac muscle. Am J Cardiol 23:516-527

13. Mason DT, Braunwald E, Covell JW, Sonnenblick EH, Roo J 1971 Assessment of cardiac contractility. The relation between the rate of pressure rise and ventricular pressure during isovolumic systole. Circulation 44:47-58

14. Wallace AG, Skinner NS, Mitchell JH 1963 Hemodynamic determinants of the maximal rate of rise of left ventricular pressure. Am J Physiol 205:3036

15. Abrahamsen AM, Grendahl H, Muller C 1972 Hemodynamic effects of methoxamine in patients with left-to-right shunt. Acta Med Scand 191:283286

16. Nejad NS, Klein MD, Mirsky I, Lown B 1971 Assessment of myocardial contractility from ventricular pressure recording. Cardiovasc Res 5:15-23

17. Siegel JH, Sonnenblick EH 1963 Isometric time-tention relationships as an index of myocardial contractility. Circ Res 12:597-610 